\title{
Comparação do perfil de sensibilidade antifúngica de isolados de Criptococcus laurentii de lesões cutâneas de pacientes diagnósticos de HIV / AIDS em um hospital público em São Luís - MA
}

\author{
Comparison of antifungal sensitivity profile of Cryptococcus laurentii isolates \\ from cutaneous lesions of patients diagnosed with hiv/aids at a public hospital \\ in São Luís - MA
}

\author{
Anna Rhaabe Braga Pinto', Hermerson Sousa Maia', Moysés Silva de Sousa², Eduardo \\ Buozi Moffa ${ }^{3}$, Silvio Gomes Monteiro ${ }^{3,4}$, Cristina de Andrade Monteiro ${ }^{3,5^{*}}$
}

Resumo: Introdução: A Criptococose é uma infecção oportunista do sistema nervoso e respiratório, no entanto, formas dérmicas podem ser manifestadas em pacientes imunossuprimidos. Objetivos: 0 objetivo deste trabalho foi determinar o perfil de sensibilidade a antifúngicos de isolados de Cryptococcus laurentii provenientes de lesões cutâneas de pacientes diagnosticados com HIV/AIDS. Dados imunológicos e epidemiológicos, a prevalência de lesões micóticas e dos micro-organismos isolados também foram relatados. Materiais e Métodos: As leveduras isoladas foram identificadas pelo sistema automatizado VITEK e o teste de sensibilidade aos antifúngicos foi realizado por meio do ensaio de microdiluição em placas. Fungos filamentosos foram identificados pelo microcultivo. Dados epidemiológicos e imunológicos foram obtidos por meio da análise de prontuários. Resultados: Quarenta e cinco por cento dos pacientes foram portadores do HIV e $22,7 \%$ apresentavam AIDS. A maior frequência foi daqueles com carga viral <1000 cópias/mL (38,6\%); 35\% eram do sexo masculino e $22,2 \%$ do sexo feminino com faixa etária entre 22 a 81 anos. A lesão mais prevalente foi onicomicose e os fungos filamentosos foram os micro-organismos mais isolados. Dentre as leveduras isolou-se $26 \%$ de Candida spp e $4 \%$ de Cryptococcus spp. Os isolados de $C$. laurentii foram sensíveis ao fluconazol, mas dose-dependente ao itraconazol e resistentes a nistatina e anfotericina B. Conclusão: Estes resultados são relevantes porque mostram a necessidade de uma pronta identificação dos micro-organismos e teste de sensibilidade para uma terapia mais adequada e eficiente.

Palavras-chave: Cryptococcus; Micose cutânea; Sensibilidade; Antifúngicos; HIV

Abstract: Introduction: Cryptococcosis is an opportunistic infection of the nervous and respiratory system; however, dermal forms may be manifested in immunosuppressed patients Objectives: The objective of this work was to determine the antifungal sensitivity profile of Cryptococcus laurentii isolates from cutaneous lesions in patients diagnosed with HIV / AIDS. Immunological and epidemiological data, the prevalence of mycotic lesions and isolated microorganisms have also been reported. Materials and Methods: The isolated yeasts were identified by the VITEK automated system and the antifungal sensitivity test was performed by means of the plaque microdilution assay. Filamentous fungi were identified by the microculture. Epidemiological and immunological data were obtained through the analysis of medical records. Results: Forty-five percent of the patients had HIV and $22.7 \%$ had AIDS. The highest frequency was those with viral load $<1000$ copies $/ \mathrm{mL}(38.6 \%)$; $35 \%$ were male and $22.2 \%$ female with an age range of $22-81$ years. The most prevalent lesion was onychomycosis and filamentous fungi were the most isolated microorganisms. Among the yeasts, $26 \%$ of Candida spp and $4 \%$ of Cryptococcus spp. C. laurentii isolates were sensitive to fluconazole but dose-dependent to itraconazole and resistant to nystatin and amphotericin $\mathrm{B}$. Conclusion: These results are relevant because they show the need for prompt identification of microorganisms and sensitivity testing for a therapy more adequate and efficient.

Keywords: Cryptococcus; cutaneous mycosis; Sensitivity; Antifungals; HIV.

\footnotetext{
${ }^{1}$ Curso de Biomedicina, Universidade Ceuma

2 Curso de Medicina, Universidade Ceuma

${ }^{3}$ Docente do Programa de Mestrado em Biologia Parasitária, Universidade Ceuma

4 Docente Departamento de Biologia da Universidade Federal do Maranhão

5 Docente Departamento de Biologia do Instituto Federal do Maranhão.
} 


\section{Introdução}

Micoses cutâneas estão entre as infecções fúngicas mais comuns e são causadas por fungos filamentosos queratinofílicos que utilizam a queratina como nutriente durante a infecção de pele, cabelo e unha ${ }^{1}$. Embora as infecções pelos dermatófitos sejam usualmente restritas a epiderme superficial, estes fungos podem acometer tecidos mais profundos e causar infecções mais severas em pacientes imunocomprometidos ${ }^{2}$.

A Síndrome da

Imunodeficiência Adquirida (AIDS) caracteriza-se por uma severa depressão celular, o que favorece a ocorrência de infecções oportunistas, principalmente por fungos filamentosos não dermatófitos e por leveduras dos gêneros Candida, Trichosporon e Cryptococcus ${ }^{3}$. Micoses cutâneas e sistêmicas estão entre a maior causa de morbidade e mortalidade entre pacientes diagnosticados com AIDS e com a Doença de Reconstituição Imune $(\mathrm{IRD})^{4}$.

Cryptococcus neoformans e C. gattii são importantes agentes etiológicos da neurocriptococcose fúngica ${ }^{5}$. A criptococcose ocorre principalmente em pacientes imunossuprimidos, associada a quadros de desordem proliferativa na linfa, terapia com esteroides, pacientes transplantados e diagnosticados com AIDS $^{6}$. Além de causar uma infecção oportunista no sistema nervoso central e pulmões, a criptococcose pode se manifestar em formas extraneurais e não pulmonares, como manifestações cutâneas, podendo ser sintomática apresentando pápulas, abscessos, celulites, lesões acneiformes, drenagem dos seios, edemas subcutâneos, ou assintomática ${ }^{6,7}$. Outras espécies como $C$. laurentii, $C$. luteolus, C. albidus, $C$. diffluens e $C$. uniguttulatus também são encontrados em isolados clínicos humanos ${ }^{8}$.

C. laurentii, considerado um patógeno humano raro, é descrito como um agente infeccioso na pele, em queratites, vias respiratórias orofaríngeas, em endoftalmites, abscesso pulmonar, pneumonia, peritonite, meningite e fungemia ${ }^{9,10,11}$.

A sensibilidade in vitro das espécies de Cryptococcus a antifúngicos ainda não está inteiramente elucidada, embora essa informação seja inteiramente importante para a escolha do antifúngico durante 0 tratamento clínico $^{12}$. Os estudos sobre a sensibilidade e resistência a antifúngicos das diversas espécies deste gênero encontram-se escassos, ocorrendo uma maior predominância de pesquisas sobre espécies clínicas e ambientes de $C$. neoformans ${ }^{13,14}$. Pacientes infectados com $C$. laurentii são tratados com anfotericina $B$ e fluconazol, de acordo com as metodologias de tratamento de infecção com o complexo $C$. neoformans, dependendo das condições clínicas e do órgão envolvido ${ }^{15}$.

No entanto, resistência a fluconazol e anfotericina $B$ já tem sido relatada, tornando dessa forma 0 tratamento mais complicado e em alguns casos sem êxito em pacientes diagnosticados com AIDS ${ }^{7}$.

\footnotetext{
${ }^{1}$ Curso de Biomedicina, Universidade Ceuma

2 Curso de Medicina, Universidade Ceuma

3 Docente do Programa de Mestrado em Biologia Parasitária, Universidade Ceuma

${ }^{4}$ Docente Departamento de Biologia da Universidade Federal do Maranhão

${ }^{5}$ Docente Departamento de Biologia do Instituto Federal do Maranhão.
} 
complexo $C$. laurentii não é bem estudado, nem há padrões previamente estabelecidos para verificação da susceptibilidade de Cryptococcus spp in vitro, mas 0 aumento de infecções associadas ao complexo enfatiza a importância dos esforços para uma identificação rápida e precisa de isolados, além da determinação do perfil de sensibilidade.

Desta forma, o objetivo deste trabalho foi determinar o perfil de sensibilidade de antifúngicos contra isolados de Cryptococcus laurentii provenientes de lesões cutâneas de pacientes diagnosticados com HIV/AIDS. Dados imunológicos e epidemiológicos, a prevalência de lesões micóticas nestes pacientes e dos micro-organismos isolados também foram relatados.

\section{MATERIAL E MÉTODOS Coleta, isolamento e identificação dos micro-organismos}

Foram coletadas amostras de lesões de micoses cutâneas de 21 pacientes portadores de HIV/AIDS, submetidos à terapia antiviral e alguns à terapia antifúngica internados em Hospital de Referência na cidade de São Luís - MA, Brasil. Para classificação de pacientes com AIDS e pacientes HIV positivo adotamos os critérios estabelecidos pelo Ministério da Saúde (contagem de linfócitos $T$ CD4+ $<350$ células $\left./ \mathrm{mm}^{3}\right)^{16}$. A pesquisa foi previamente aprovada pelo Comitê de Ética da Universidade CEUMA sob o parecer №: 63522/2012

As amostras foram coletadas utilizando-se lancetas ou swabs estéreis, acondicionadas em tubos estéreis e transportadas imediatamente ao Laboratório de Pesquisa em Micologia Médica da Universidade CEUMA para cultivo e identificação das espécies fúngicas.
Todos os pacientes foram submetidos à higiene do local de coleta das amostras com álcool $70 \%$. O método de raspagem com lanceta ou bisturi estéril, foi utilizado para obter escamas de pele de bordos ativos das lesões. Para obtenção do leito subungueal das unhas dos pacientes usou-se curetas ou espátulas estéreis no intuito de colher escamas bem finas, priorizando 0 tecido ungueal recém invadido e descartando a parte mais antiga. Para coleta de cabelos ou pelos foram utilizadas pinças ou tesouras.

O material coletado foi transportado imediatamente ao laboratório e sujeito a exame micológico direto (EMD) com $\mathrm{KOH}$ (Hidróxido de potássio) variando a sua concentração de acordo com a amostra examinada (10\% a 30\%). O isolamento dos micro-organismos foi feito em Sabouraud Dextrose Ágar com cloranfenicol (SDA, Difco, Detroit, $\mathrm{MI}$, USA) durante $48^{\circ}$ horas a $37^{\circ} \mathrm{C}$ (leveduras) ou $28^{\circ} \mathrm{C}$ (fungos filamentosos). Os espécimes leveduriformes foram estocadas à $4^{\circ} \mathrm{C}$ durante 0 período experimental, renovadas a cada dez dias para manutenção das suas propriedades e a sua recuperação foi realizada em meio sólido específico por $24 \mathrm{~h}$ à $37^{\circ} \mathrm{C}$. Já as amostras filamentosas foram mantidas em água destilada estéril em temperatura ambiente e sob refrigeração em SDA. Para identificação das amostras colhidas utilizou-se o meio cromogênico CHROmagar Candida ${ }^{\circledR}$ (Difco, Detroit, MI, USA) e o método automatizado VITEK 2 (Vitek-2 Compact bioMérieux, Marcy-l'Étoile, France)

A identificação dos fungos filamentosos foi baseada na análise de estruturas microscópicas, comparados com os aspectos macromorfologicos. Para a análise das estruturas 
microscópicas foi realizado 0 microcultivo, segundo a metodologia tradicional proposta por Riddell ${ }^{17}$. Para observação das estruturas macroscópicas, os fungos foram inoculados por ponto central em placas de Petri contendo meio SDA, verificando-se características como tamanho, pigmentação e aspectos da forma e textura, e topografia do verso e reverso da colônia na placa ${ }^{18}$. As chaves de identificação consultadas foram de Lacaz e colaboradores ${ }^{19}$.

\section{Dados de prontuários}

Dados epidemiológicos e imunológicos bem como medicação administrada, presença ou não de infecção e tipos de lesões foram obtidos por meio da análise de prontuários.

\section{Preparação do inóculo padronizado}

Para a preparação do inóculo, a suspensão das células foi realizada em meio BHI (Brain Heart Infusion Acumedia Manufactures) ou RPMI1640 líquido (Sigma Aldrich, Brasil), centrifugada a 1500rpm por dez minutos e lavada com PBS (Tampão salina fosfato) de $\mathrm{pH}$ neutro, para posterior padronização com a escala de McFarland 0,5 que corresponde à aproximadamente $10^{7} \mathrm{UFC} / \mathrm{mL}$ de acordo com o Clinical and Laboratory Standards Institute ${ }^{20}$.

\section{Ensaio de microdiluição}

A concentração inibitória mínima (CIM) dos antifúngicos Itraconazol (ITRA), Fluconazol (FLU), Nistatina (NIS) e Anfotericina B (AMB) (Sigma Aldrich, Brasil) foi determinada pelo ensaio de microdiluição em caldo de acordo com Clinical and Laboratory Standards Institute 20 .

Uma solução padrão $10 \mathrm{x}$ concentrada de cada antifúngico foi preparada em solventes específicos.
Diluições seriadas em meio RPMI1640 foram realizas para obtenção de concentrações variando de 32 a $0,0625 \mu \mathrm{g} / \mathrm{mL}$ para $A M B$, de 16 a 0,03 $\mu \mathrm{g} / \mathrm{mL}$ para ITRA e de 128 a 0,25 $\mu \mathrm{g} / \mathrm{mL}$ para FLU e NIS ${ }^{20}$.

$O$ inóculo padronizado foi diluído duas vezes em meio de cultura RPMI-1640 para obtenção de uma concentração de $5 \times 10^{3}$ células $/ \mathrm{mL}$ e $100 \mu \mathrm{L}$ deste foram distribuídos em microplaca de 96 poços. Em seguida $100 \mu \mathrm{L}$ de antifúngicos diluídos foram adicionados. Poços sem a droga/substância foram usados como controle de crescimento, além de poços somente com o meio de cultura foi utilizado como controle de esterilidade. As placas foram incubadas à $37^{\circ} \mathrm{C}$ por $48 \mathrm{~h}$.

A CIM dos antifúngicos foi determinada após 48 horas com leitura das microplacas em leitor de ELISA (bioMérieux Reader 250 Version 2.0.5) a 450nm. O valor de CIM de Anfotericina $B$ é definido como a menor concentração em que se observa o campo opticamente claro, sendo o CIM de azóis definido como a menor concentração em que se observa redução proeminente de crescimento $(50 \%$ da inibição do crescimento). Para Fluconazol amostras com CIMs $\leq 8 \mu \mathrm{g} / \mathrm{mL}$ foram consideradas sensíveis (S), entre 16$32 \mu \mathrm{g} / \mathrm{mL}$ como sensíveis dosedependentes (SDD) e $\geq 64 \mu \mathrm{g} / \mathrm{mL}$ como resistentes $(R)$. Para Itraconazol isolados com CIMs $\leq 0,125 \mu \mathrm{g} / \mathrm{mL}$ foram considerados sensíveis, entre 0,25-0,5 $\mu \mathrm{g} / \mathrm{mL}$ foram SDD e $\geq 1 \mu \mathrm{g} / \mathrm{mL}$ classificados como R. Para Nistatina amostras com CIMs $>16 \mu \mathrm{g} / \mathrm{mL}$ considerados resistentes $(\mathrm{R})$. Com relação a Anfotericina $\mathrm{B}$ CIMs $<1$ foram considerados sensíveis $e>2$ $\mu \mathrm{g} / \mathrm{mL}$ resistentes ${ }^{20}$.

\section{Aspectos Éticos da Pesquisa}


A coleta das amostras de fungos seguiu rigorosamente as normas da Resolução CNS 196/96. O projeto foi aprovado pelo CEP/UNICEUMA sob Parecer consubstanciado N. 63522 de 28/05/2012 e CAAE 00855812.8 .0000 .5084 .

Os indivíduos que participaram da pesquisa foram previamente elucidados quanto ao estudo a ser desenvolvido e aqueles que concordaram em participar, assinaram o Termo de Consentimento Livre e Esclarecido e foram incluídos na amostra. Os procedimentos de coleta foram realizados em consultório médico por profissional habilitado, possuidor de material esterilizado e descartável, sem qualquer uso de técnicas invasivas ou cirúrgicas ou quaisquer procedimentos que causem danos biológicos ao paciente.

As amostras foram processadas no Laboratório de Micologia Médica da
Universidade Ceuma do seguindo as Normas de Biossegurança para manipulação de micro-organismos.

\section{Análise dos dados}

Todos os resultados obtidos nesta pesquisa foram expressos na forma de números, tabulados e ilustrados assim como, gráficos e tabelas utilizando o software PRISM (GraphPad Software) versão 5.0.

\section{RESULTADOS}

Foram realizadas coletas em 44 pacientes atendidos em hospital de referência em São Luís. Entre os pacientes participantes da pesquisa 20 $(45,5 \%)$ eram apenas portadores do HIV, e 10 (22,7\%) já eram considerados pacientes com AIDS, de acordo com os critérios estabelecidos pelo Ministério da Saúde (BRASIL, 2004) (Figura 1).

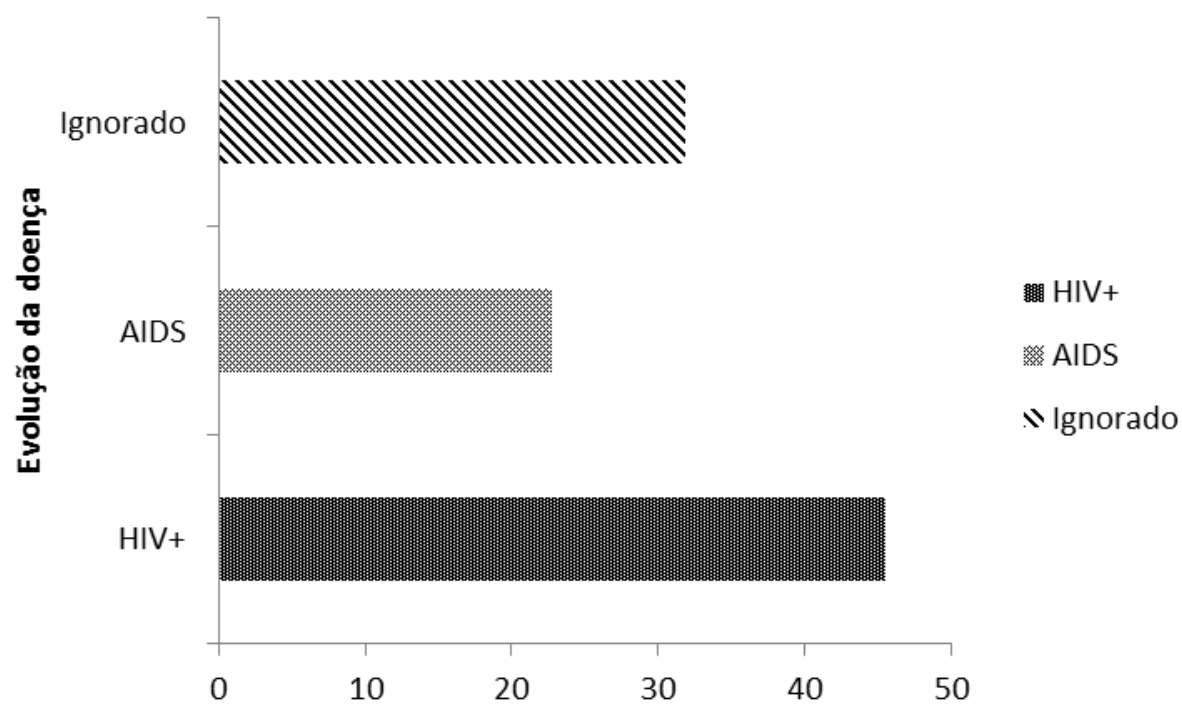

Figura 1 - Porcentagem de pacientes internados em Hospital de Referência em São Luís -Ma e classificados como portadores de HIV ou com AIDS. Ignorado = sem notificação do número de CD4.

Em relação à carga viral, foi observado que dentre os pacientes que tinham esses dados disponíveis, a maior frequência foi de pessoas com carga viral $<1000$ cópias $/ \mathrm{mL}$ com $38,6 \%$, enquanto que $2,3 \%$ apresentaram carga viral entre 1000 4000 e 10.000-30.000, 68\% apresentaram entre 4000-10.000 e 50.000-100.000 cópias/mL (Figura 2). 


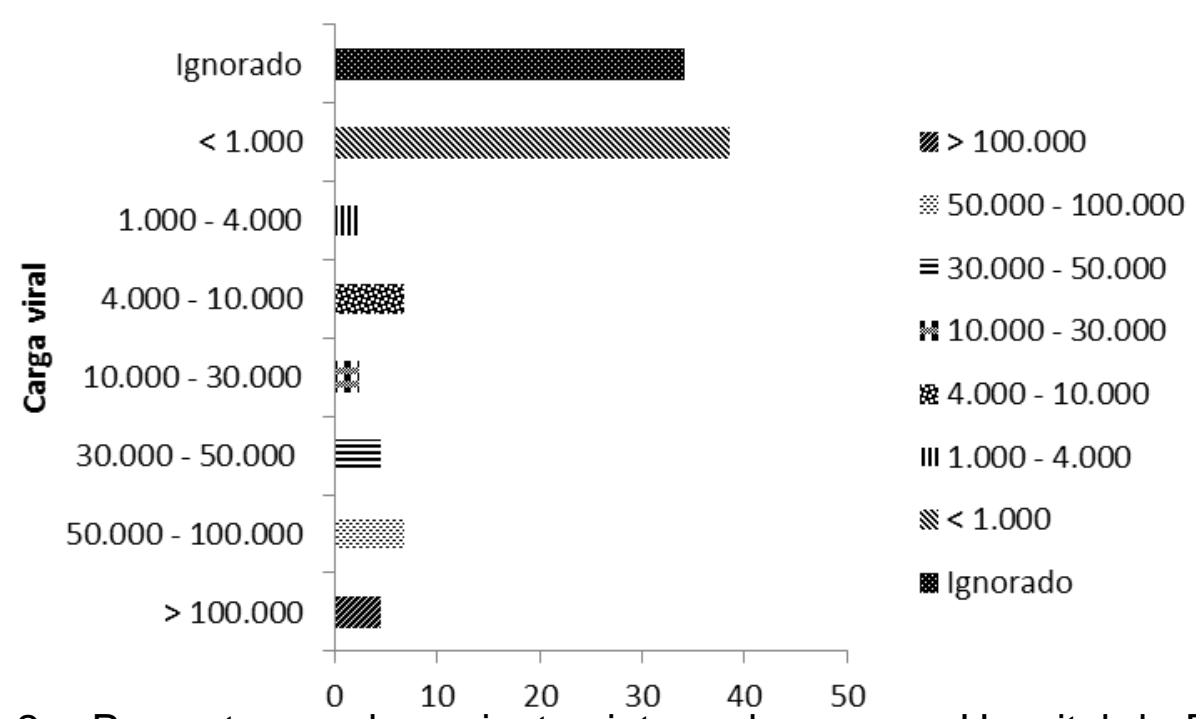

Figura 2 - Porcentagem de pacientes internados em um Hospital de Referência em São Luís-Ma em relação à quantificação da carga viral

Baseado na análise dos dados sócio demográficos observou-se que dos 44 pacientes que participaram da pesquisa, $35 \%$ (34) eram do sexo masculino e $22,2 \%$ (10) do sexo feminino. Quanto à faixa etária, foram verificadas pessoas com faixa etária entre 22 a 81 anos. Quanto à escolaridade constatou-se que a maioria das pessoas que participou da pesquisa tinha menos de oito anos de estudo.
Neste trabalho avaliou-se também a frequência do tipo de lesão fúngica cutânea entre os pacientes. Verificou-se que a onicomicose foi a mais prevalente (66\%) (Figura 3). Dezesseis por cento dos pacientes apresentaram mais de um tipo de lesão e $11 \%$ mostraram um só tipo de lesão, entretanto com manifestação em várias localizações pelo corpo ao mesmo tempo

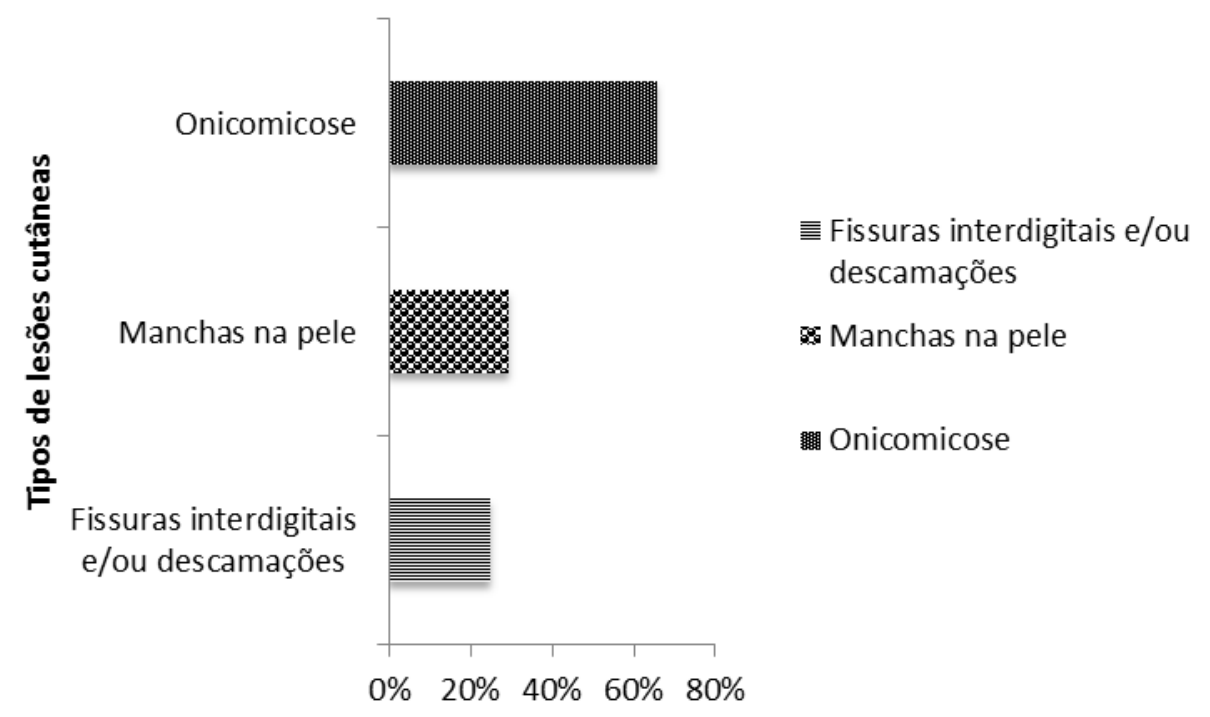

Figura 3 - Frequência de lesões cutâneas clinicamente observadas nos pacientes com HIV/AIDS 
Entre os fungos isolados de todas as lesões, os fungos filamentosos apresentaram maior frequência (40\%) (Figura 4). Dentre as leveduras identificou-se $70 \%$ do gênero Candida, $23 \%$ de Trichosporon e $8 \%$ de Cryptococcus (2 isolados).

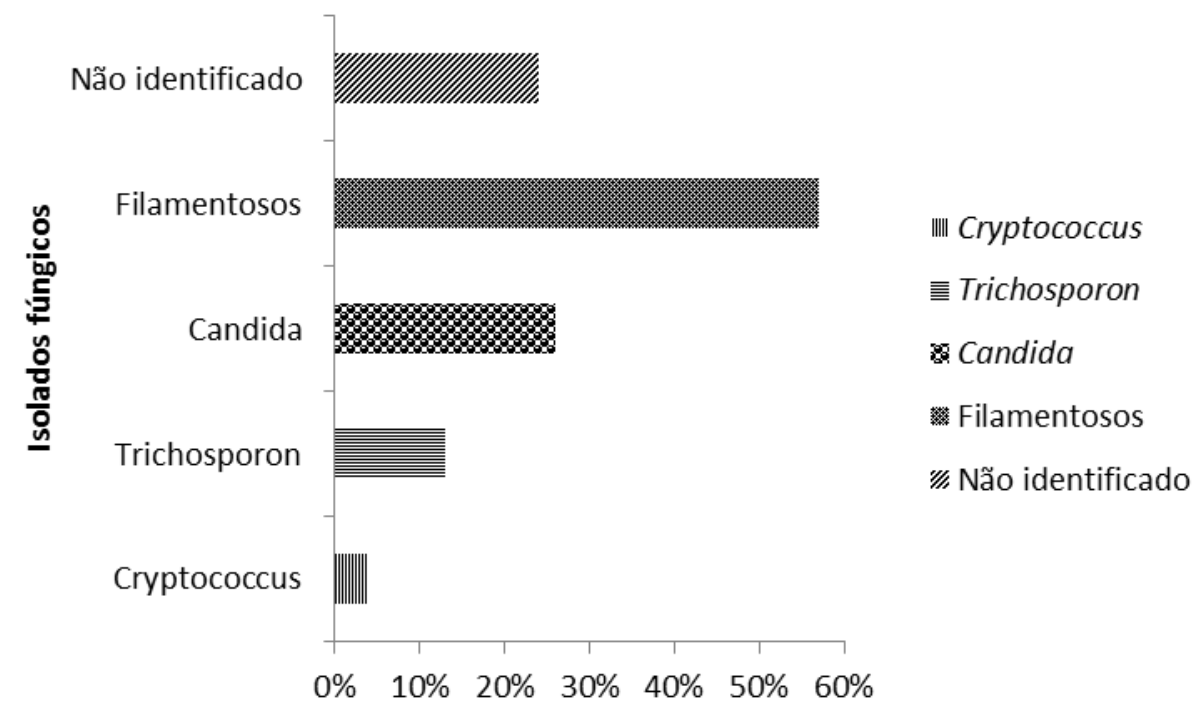

Figura 4 - Frequência de isolados fúngicos obtidos das lesões cutâneas dos pacientes com HIV+/AIDS.

Entre os fungos isolados apenas de onicomicose, a maior prevalência foi de fungos filamentosos (55\%), seguido por isolados do gênero Candida (39\%).

Dentre os pacientes analisados, apenas dois apresentaram Cryptococcus laurentii isolados de lesões de onicomicose (denominados isolados C/A e C/B). Ambos os isolados foram provenientes de onicomicose de membro inferior esquerdo. Ambos os pacientes estavam sob terapia antirretroviral e o paciente do isolado $C / B$ estava fazendo uso de antifúngicos fluconazol e miconazol.

Em relação ao perfil sorológico, o paciente do isolado CIA apresentou uma carga viral de 1.000 cópias $/ \mathrm{mL}$ e uma contagem de células CD4 igual a 441 células $/ \mathrm{mL}$, por outro lado 0 paciente do isolado $C / B$ exibiu uma carga viral de 5.585 cópias $/ \mathrm{mL}$ e uma contagem de células CD4 igual a 168 células/mL (Figura 5).

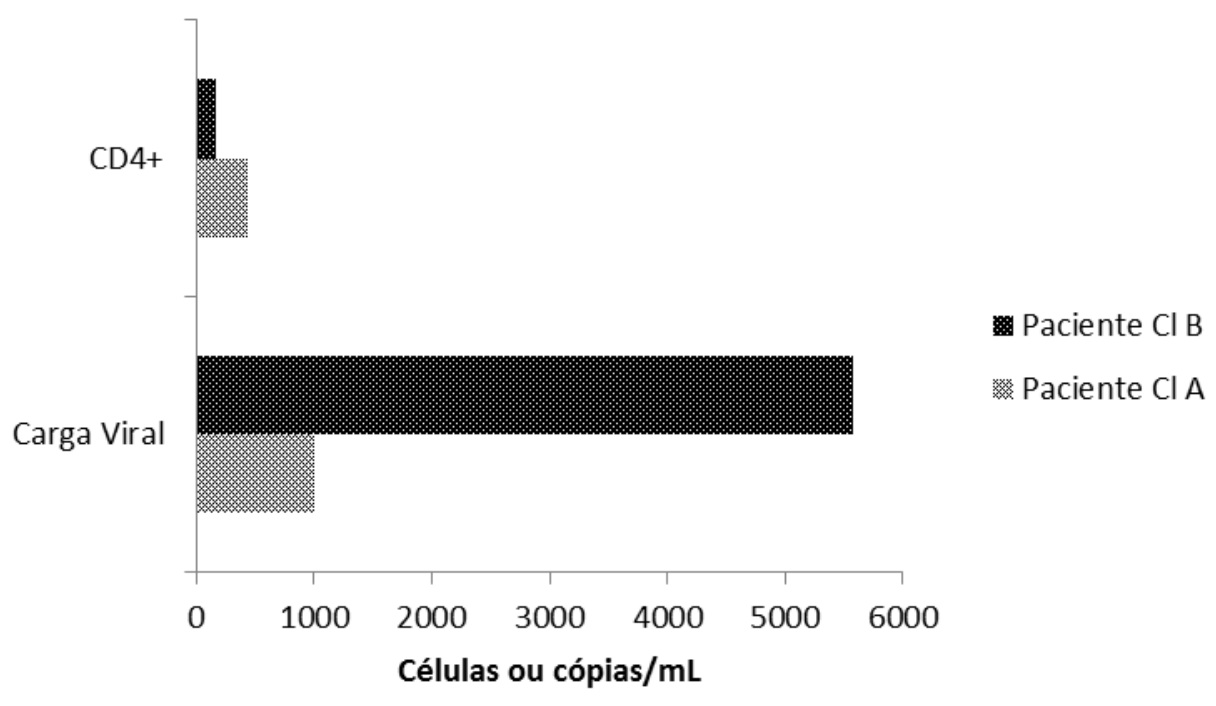


Figura 5 - Número de células CD4+ e da carga viral dos pacientes (Paciente $\mathrm{Cl}$ A e Paciente $\mathrm{Cl} \mathrm{B}$ ) com Cryptococcus laurentii isolados de onicomicose.

Em relação ao perfil de sensibilidade as duas amostras foram sensíveis ao fluconazol com $\mathrm{CIM}_{50}$ de $2 \mu \mathrm{g} / \mathrm{mL}$ para $\mathrm{o}$ isolado CIA e de 4 $\mu \mathrm{g} / \mathrm{mL}$ para o $\mathrm{C} / \mathrm{B}$. Ambos os isolados apresentaram uma sensibilidade dosedependente para o itraconazol ( $\mathrm{CIM}_{50}$ de $0,25 \mu \mathrm{g} / \mathrm{mL}$ para CIA e CIM50 de 0,5 $\mu \mathrm{g} / \mathrm{mL}$ para $C / B)$ e resistência para nistatina (CIM50 de $64 \mu \mathrm{g} / \mathrm{mL}$ para CIA e C/B) e anfotericina $B\left(\mathrm{CIM}_{50}\right.$ de 32 $\mu \mathrm{g} / \mathrm{mL}$ para CIA e CIM50 de $16 \mu \mathrm{g} / \mathrm{mL}$ para $C / B)$.

\section{DISCUSSÃO}

Dentre os pacientes que participaram desta pesquisa dez foram diagnosticados com AIDS, a maioria era do sexo masculino e tinha um baixo nível de escolaridade. Isto demonstra que houve mudanças no quadro epidemiológico, com maior frequência de AIDS em pessoas heterossexuais, com baixo nível escolar e passando a atingir não apenas indivíduos de regiões metropolitanas como também aqueles das demais cidades da região ${ }^{21}$. Nos estudos de Torres e Luz ${ }^{22}$, Lima e Costa $^{23}$, mostraram que há relação inversamente proporcional entre a quantidade de anos de estudo e a ocorrência da infecção pelo HIV.

As onicomicoses foram o tipo de lesão fúngica cutânea mais prevalente encontrado nesta pesquisa. CAMBUIM e colaboradores ${ }^{24}$ descrevem que as onicomicose são causadas principalmente por leveduras, dermatófitos e outros fungos filamentosos, sendo a infecção superficial mais comum em pacientes aidéticos, o que corrobora os achados nesta pesquisa. Entretanto, as onicomicoses ocorrem tanto em pessoas imunossuprimidas como em pessoas imunocompetentes ${ }^{25}$. Em paciente HIV positivos, esta micose pode ocorrer em mais de $30 \%$ dos pacientes, principalmente quando a contagem de linfócitos T CD4 estiver abaixo de 400 células $/ \mathrm{mm}^{26}$. Estes pacientes são alvo constante das onicomicoses, fato frequentemente observado na prática médica ${ }^{27}$. Este fato sugere maior atenção, pois estas infecções cutâneas podem evoluir para quadros mais graves, principalmente em pacientes imunocomprometidos.

A maior frequência de fungos encontrada foi a de filamentosos seguida por leveduras do gênero Candida e por Cryptococcus. Estes dados diferem dos de ARAUJO et al ${ }^{28}$ que relatam uma maior prevalência de dermatófitos (80-90\%) como agentes de onicomicose, seguido das leveduras (5-17\%). Porém, Reichenberg e colaboradores ${ }^{29}$, mostraram que o isolamento de fungos filamentosos em amostras clínicas foi observado com mais frequência em pacientes imunocomprometidos. Os dois isolados de Cryptococcus foram da espécie C. laurentii.

Nos últimos anos, quadros de criptococcose causados por Criptococcus não neoformans estão cada vez aumentando, sendo a prevalência de infecções por $C$. laurentii baixa, uma vez que este patógeno por muito tempo foi considerado como saprófito e não patogênico para seres humanos. No entanto, em situações oportunistas, como uma baixa supressão do sistema imune, este micro-organismo desempenha um papel inteiramente importante, como descrito por FURMAN-KUKLINSKA et $\mathrm{al}^{30}$. Cryptococcus laurentii é extremamente 
raro como patógeno no homem. Uma revisão de literatura mostrou somente 3 casos de infecção cutânea por Cryptococcus laurentii. Todos os casos ocorreram em pacientes imunocomprometidos ${ }^{31,11,32,33}$. Esta informação corrobora com o achado desta espécie nas lesões dos participantes portadores de AIDS nesta pesquisa. Contudo, MolinaLeyva e colaboradores ${ }^{33}$ relataram pela primeira vez infecção cutânea por $C$. laurentii em paciente imunocompetente.

Pouco tem sido descrito sobre o perfil de sensibilidade de Criptococcus não neoformans a antifúngicos, a maioria dos relatos são fornecidos por estudo de casos (p. ex., Molina-Leyva et al., $\left.{ }^{33}\right)$. Os isolados aqui analisados foram sensíveis a fluconazol (CIMs de 2 e $4 \mu \mathrm{g} / \mathrm{mL}$ ), mas dose-dependentes a itraconazol (CIMs de 0,25 e 0,5 $\mu \mathrm{g} / \mathrm{mL}$ ) e resistentes a anfotericina $B$ (CIMs de 32 e $16 \mu \mathrm{g} / \mathrm{mL}$ ) e nistatina (CIMs de $64 \mu \mathrm{g} / \mathrm{mL}$ ). A maioria dos isolados descritos na literatura é sensível a anfotericina, porém $C$. laurentii resistentes a este antifúngico já foram relatados por MICELI et $\mathrm{al}^{34}$ em dois pacientes que tiveram esta droga como medicação. Os resultados aqui obtidos são relevantes porque um relatório sobre as diretrizes práticas para o manejo da infecção criptocócica recomenda o uso de azóis para infecções criptocócicas não associadas do sistema nervoso central, incluindo doenças cutâneas (Perfect et al., ${ }^{7}$ ).

Segundo

colaboradores $^{34}$, o fluconazol possui baixa ação contra Criptococcus não neoformans, sendo a resistência uma caracterísica mais frequente em pacientes com exposição prévia aos azóis. Esta informação discorda com o achado neste trabalho, já que os dois isolados encontrados de $C$. laurentii demonstraram-se sensíveis a este antifúngico. Embora Miceli ${ }^{34}$ tenha demonstrado resistência de isolados a fluconazol, a literatura já descreve casos de fungemia por $C$. laurentii tratados com sucesso utilizando este antifúngico ${ }^{30,33}$.

Tabela 1| Concentração Inibitória Mínima $\left(\mathrm{CIM}_{50}\right)$ em $\mu \mathrm{g} / \mathrm{mL}$ dos antifúngicos para os isolados de Cryptococcus laurentii provenientes de lesões cutâneas.

\begin{tabular}{llllll}
$\begin{array}{l}\text { Antifúngico } \\
(\mu \mathrm{g} / \mathrm{mL})\end{array}$ & $(\mathrm{S})$ & $(\mathrm{S}-\mathrm{DD})$ & $(\mathrm{R})$ & $\begin{array}{l}\text { Isolado } \\
\text { C/A }\end{array}$ & $\begin{array}{l}\text { Isolado } \\
\mathrm{C} / \mathrm{B}\end{array}$ \\
\hline Itraconazol & $\leq 0,125$ & $0,25-0,5$ & $\geq 1$ & 0,25 & 0,5 \\
Fluconazol & $<8$ & $16-32$ & $\geq 64$ & 2 & 4 \\
Anfotericina B & $<1$ & - & $\geq 1$ & 32 & 16 \\
Nistatina & $\leq 4$ & $8-32$ & $\geq 64$ & 64 & 64 \\
\hline
\end{tabular}

*'S: Sensível, S-DD: Sensibilidade Dose Dependente, R: Resistente.

\section{CONCLUSÃO}

Embora Cryptococcus laurentii seja extremamente raro como patógeno humano, o isolamento desta espécie em pacientes imunocomprometidos requer 0 conhecimento do perfil de sensibilidade às drogas antifúngicas para que uma terapia adequada seja adotada. Os isolados de C. laurentii foram sensíveis a fluconazol, mas sensíveis-dose dependentes à itraconazol (azólico) e resistentes a nistatina e anfotericina B (polienos). Estes dados são relevantes, pois confirmam o uso de azóis, como o 
fluconazol, para o manejo de infecção por criptococos. Além disso, os resultados confirmam a onicomicose como lesão mais frequente e o índice relativamente alto de leveduras isoladas.

\section{REFERÊNCIAS}

1 Vermout S, Tabart J, Baldo A, Mathy A, Losson B, Mignon B. Pathogenesis of dermatophytosis. Mycopathologia. 2008; 166:267-75;

2 Rodwell GE, Bayles CL, Towersey L, Aly $R$. The prevalence of dermatophyte infection in patients infected with human immunodeficiency virus. Int $\mathrm{J}$ Dermatol. 2008;47:339-43.

3 Peres NTA, Maranhao FCA, Rossi A, Martinez-Rossi NM. Dermatophytes: host-pathogen interaction and antifungal resistance. An Bras Dermatol. 2010;85(5):657-67.

4 Nacher M, Vantilcke V, Mahamat A, Guedj ME, Vaz, T, Randrianjohany A. Increased incidence of cutaneous mycoses after HAART initiation: a benign form of immune reconstitution disease? Research Letters AIDS. 2007; 21:2243-2250.

5 Ajesh, K, Sreejith, K. Cryptococcus laurentii Biofilms: Structure, Development and Antifungal Drug Resistance.

2012;174: 409 - 419.

6 Subramanian S, Mathai D. Clinical manifestations and management of cryptococcal infection. J Postgrad Med, 2005; 51(1): 521-526.

7 Perfect JR, Dismukes WE, Dromer F, Goldman DL,Graybill JR. Clinical practice guidelines for the management of cryptococcal disease:2010 update by the Infectious Diseases Society of America. Clin Infect Dis 2010;50:291-322.

8 Heitman J, Kozel TR, Kwon-Chung KJ, Perfect JR, and Casadevall A. Cryptococcus: From Human Pathogen to Model Yeast. Washington, D.C., ASM Press, 2011.620pp;

9 Kordossis T, Avlami A, Velegraki A, Stefanou L, Georgakopoulos G, Papalambrou C, Legakis NJ. First report of Cryptococcus laurentii meningitis and a fatal case of Cryptococcus albidus cryptococcaemia in AIDS patients. Med Mycol, 1998; 36:335-339.

10 Bauters TG, Swinne D, Boekhout T, Noens L, Nelis HJ. Repeated isolation of Cryptococcus laurentii from the oropharynx of an immunocompromised patient. Mycopathologia 153: 133-135, 2002.

11 Vlchkova-Lashkoska M, Kamberova S, Starova A, Goleva-Mishevska L, Tsatsa-Biljanovska N, Janevska V, Petrovska M. Cutaneous Cryptococcus laurentii in a human immunodeficiency virus-negative subject. J Eur Acad Dermatol Venereol, 2004; 18:99-100.

12 Ferreira-Paim K, Andrade-Silva L, Mora DJ, Lages-Silva E, Pedrosa AL, Silva PR, Andrade AA, Silva-Vergara ML. Antifungal susceptibility, enzimatic activity, PCR-fingerprinting and ITS sequencing of environmental Cryptococcus laurentii isolates from Uberaba, Minas Gerais, Brazil. Mycopathologia, 2012; 174: 41-52.

13 Moraes EM, Primola NS, Hamdan JS. Antifungal susceptibility of clinical and environmental isolates of Cryptococcus neoformans to four antifungal drugs determined by two techniques. Mycoses. 2003;46: 164168.

14 Pedroso RS, Ferreira JC, Candido $\mathrm{RC}$. In vitro susceptibility to antifungal agents of environmental Cryptococcus spp. isolated in the city of Ribeirão Preto, São Paulo, Brasil. Mem Inst Oswaldo Cruz, 2006; 101:239-243.

15 Pedroso RS, Ferreira JC, Costa KRC, Candido RC. Evaluation of The Disk Diffusion Method For Testing Fluconazole Susceptibility of 
Cryptococcus laurentii. Rev Patol Trop Vol, 2013; 42 (1): 42-48.

16 Brasil, Ministério Da Saúde (Br). Secretaria De Vigilância Em Saúde. Programa Nacional De Dst E Aids. Critérios De Definição De Casos De Aids. 2004.

17 Riddell RW. Permanent stained mycological preparations obtained by slide culture. Mycologia, 1950; 42:265.

18 LACAZ CS.; PORTO E. Tratado de Micologia Médica. São Paulo: Editora Sarvier; 2002.

19 Lacaz, CS.Guia Para Identificação de Fungos, Actinomicetos e Algas de interesse médico, 8a ed., Sarvier, São Paulo, 1998.

20 CLSI. Clinical and Laboratory Standards Institute. (NCCLS. National Committee for clinical Laboratory Standards). Reference Method for Broth Dilution Antifungal Susceptibility Testing of Yeast. Approved standart M27-A2. Wayne, National Committee for clinical Laboratory Standards, 2008;

21 Schuelter-Trevisol F, Pucci P, Justino AZ, Nicole Pucci. Perfil epidemiológico dos pacientes com HIV atendidos no sul do Estado de Santa Catarina, Brasil Epidemiol. Serv. Saúde, 2010; 22 (1).

22 Torres SR, Luz AMH. Gestante HIV+ e crianças expostas: estudo epidemiológico da notificação compulsória. Rev Gaúcha Enferm, 2007; 28:505-511.

23 Lima ACM, Costa CC, Teles LMR, Damasceno AKC, Oria Mob. Avaliação epidemiológica da prevenção da transmissão vertical do HIV. Acta Paul Enferm, 2012; 27:311-318.

24 Cambuim IIFF, Macedo DPC, Delgado M, Lima KM, Mendes GP, Souza-Mota CM, Lima DMM, Fernandes MJ, Magalhães OMC, Queiroz LA, Neves RP. Clinical and mycological evaluation of onychomycosis among Brazilian
HIV/AIDS patients. Revista da Sociedade Brasileira de Medicina Tropical, 2011; 44: 40-42.

25 Schmidt BM, Holmes C. Proximal White onychomycosis in na immunocompetent patient: A case report. Scientific Researchm Publishing. 2015; 4:41-44.

26 Dahdah, MJ, Scher RK. Onychomycosis - an overview. US: Dermatology review; 2006.

27 Vender RB. Lynde CW, Poulin Y.Prevalence and epidemiology of onychomycosis. J Cutan Med Surg, 2006; 10:28-33.

28 Araújo AJG, Bastos OMP, Souza MAJ, Oliveira JC. Onychomycosis caused by emergent fungi: clinical analysis, diagnosis and revision. An Bras Dermatol, 2003; 78:445-455.

29 Reichenberg F, Habicht JM, Gratwohl A, Tamm M. Diagnosis and treatment of invasive pulmonar aspergillosis in neutropenic patients. Eur Respir J, 2002; 19:743-755.

30 Furman-Kuklinska K, Naumnik B. Mysliwiec M. Fungaemia due to Cryptococcus laurentii as a complication of immunosuppressive therapy --a case report. Adv Med Sci. 2009; 54(1): 116-9. 31 Kamalam A, Yesudian $P$, Thambiah AS. Cutaneous infection by Cryptococcus laurentii. $\mathrm{Br} \mathrm{J}$ Dermatol, 1997; 97:221-223.

32 Kulkarni, Sinha, Anandh, Kulkarni A, Sinha M, Anandh U. Primary cutaneous cryptococcosis due to Cryptococcus laurentii in a renal transplant recipient. Saudi J Kidney Dis Transpl 2012;23:102-5.

33 Molina-Leyva A, Ruiz-Carrascosa JC, Leyva-Garcia A, Husein-Elahmed $\mathrm{H}$. Cutaneous Cryptococcus laurentii infection in na immunocompetent child. International Journal of Infectious Diseases, 2013; 17: 1232-1233.

34 Miceli MH, Díaz JA, Lee SA. Emerging opportunistic yeast infections. Lancet Infecct Dis, 2011; 11:142-51. 